\title{
THE EFFECT OF WAVES ON RUBBLE-MOUND STRUCTURES
}

\author{
Fredric Raichlen \\ W. M. Keck Laboratory of Hydraulics and Water Resources \\ California Institute of Technology, Pasadena, California 91109
}

\section{INTRODUCTION}

For thousands of years breakwaters have been built at or near the coast to protect harbors or coastlines from wave attack. One of the earliest known harbor protection schemes was devised in about 2000 B.C. for the Port of Pharos on the open coast of Egypt; it had a rubble-mound breakwater approximately $8500 \mathrm{ft}$ long composed of large blocks of stone with smaller stone filling the spaces between blocks (Savile 1940).

Until the development of experimental laboratory techniques to investigate the effect of waves on breakwaters, these structures were designed primarily from experience gained from other similar structures. It is the purpose of this review to discuss various aspects of the hydrodynamics of wave attack on such structures and the relation of certain analytic considerations and experimental results to the design of a rubble-mound.

A breakwater built as a rubble-mound is constructed by placing material of various sizes layer by layer (or unit by unit) until the desired cross-section shape is achieved. Generally, the units are not structurally connected, so that the integrity of the rubble-mound depends on features such as the weight of the material, the interlocking nature of the material, and the cross section of the structure. Usually the structure is built with material graded from smaller sizes in the core to larger material armoring the face against wave attack. The armor layer may be composed of quarry-stone, if it is available in the required sizes and is economically feasible to use. When these conditions are not met, specially designed concrete units for armoring the face of the rubble-mound have been developed that tend to interlock better than rock when properly placed; hence, it may be possible to use armor units lighter than the required quarry-stone.

Over the years numerous geometric shapes have been developed for such armor units, with each shape generally introduced in an attempt to improve on the interlocking characteristics of its predecessors. To mention only a few, various names used for different units are: tribars, tetrapods, quadripods, and dolosse. A brief description of two of these is presented; for a more detailed discussion of 
shape along with drawings of the units the interested reader is directed to CERC (1966) and Hudson (1974). Tribars, which consist basically of three circular cylinders connected by a yoke of three cylinders, are usually placed in a uniform geometric pattern on the face of the rubble-mound. Dolosse are shaped like the letter " $\mathrm{H}$ " with the vertical legs rotated $90^{\circ}$ to each other, and are generally placed randomly on a rubble-mound face. It is the effective interlocking of dolosse that leads to the use of random placement techniques.

Obviously an important aspect in the design of a rubble-mound is its stability under wave attack. This subject is discussed in detail, along with descriptions of the basis for certain design approaches currently used. The support of these design criteria as well as their limitations are discussed with reference to available experimental data.

Three other aspects of the effect of waves on rubble-mounds are treated in this review: wave run-up, transmission, and overtopping. Run-up is defined as the vertical height above still water level to which waves incident upon a structure can be expected to travel up the face of the structure. Wave run-up is important in defining both the amount of wave energy transmitted over and through permeable rubble-mounds and also the quantity of water that may be expected to overtop the structure.

In each of the following sections the discussion is directed toward understanding the fluid-mechanic aspects of the various problems and the features and the shortcomings of analytical and experimental models used in connection with the design of breakwaters constructed as rubble-mounds.

\section{STABILITY}

\subsection{Analytical Considerations}

The integrity of a rubble-mound structure is primarily a function of the stability of the individual armor units that form the seaward (or shoreward) face of the structure. Hence, a major design criterion is to determine the minimum weight of units that will yield a prescribed percentage of damage for a given

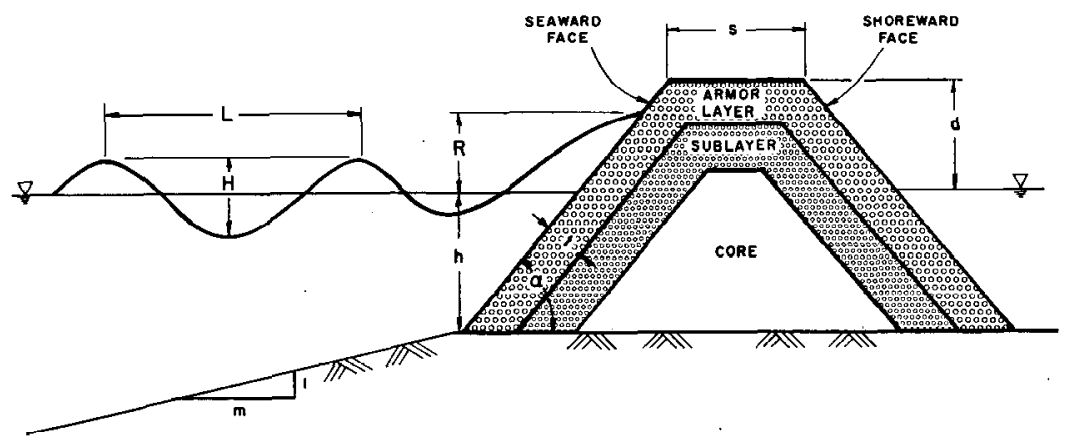

Figure 1 Definition sketch of a rubble-mound structure. 


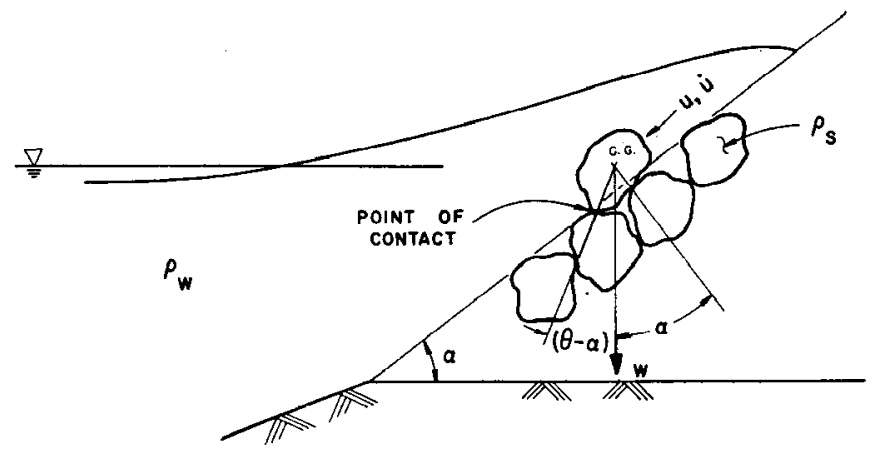

Figure 2 Definition sketch for incipient motion of armor units.

incident wave system; the condition of no damage corresponds to the incipient motion of the armor material. At the present time, incipient motion cannot be predicted analytically; thus, laboratory experiments and observations of prototype structures are necessary. As a guide to conducting such experiments and analyzing the results, dimensional analysis can be used to delineate the important parameters that affect stability. In the following discussion, important nondimensional parameters are defined for this problem, and a physical approach is described by which expressions have been developed for use in breakwater design.

A schematic drawing of a rubble-mound structure is presented in Figure 1, with the structure exposed to periodic waves (regular waves) with height $H$, wave length $L$ (or wave period $T$ ), and a water depth $h$ at the toe of the structure; the slope of the sea-bed offshore of the structure is $1 / \mathrm{m}$, and the orthogonals to the wave crests are perpendicular to the face of the structure. The rubblemound is constructed with the seaward face at an angle $\alpha$ to the horizontal using an armor layer composed of individual units of weight $W$ and density $\rho_{s}$. For this discussion the structure is assumed to be founded on an impermeable bed, and the duration of exposure to waves is not considered.

If the stable weight $W$ of an armor unit located on the seaward face of a rubble-mound (see Figure 2) can be related to variables describing the wave system and the characteristics of both the armor units and the structure, the functional relationship which includes the most important of these variables can be written as:

$$
f\left[H, T, h, j, m,\left(\rho_{s}-\rho_{w}\right), \rho_{w}, g, W, \mu, \alpha, d, s, t, p, r, S, P\right]=0,
$$

where $f[]$ indicates "function of."

The first four variables in (1) describe the wave: for waves relatively long compared to the depth, the bottom slope in combination with the wave height, wave length, and depth determine the asymmetry of the wave at the structure and the shape of the wave if it is breaking. In the next group of four variables, the buoyant density $\rho_{s}-\rho_{w}$ and dry weight $W$ of the capstone appear; the former is important since the submerged weight of the rock resists the 
action of the hydrodynamic forces imposed by the incident waves. The acceleration of gravity $g$ and the fluid density $\rho_{w}$ also are in this group. The variable $\mu$ is the dynamic fluid viscosity, which provides for viscous effects in the problem. The next group of terms describes the geometric characteristics of the rubble-mound and the armor units: the slope of the face of the structure, $\alpha$; the height of the crest of the breakwater above the mean level, $d$; the width of the crown of the structure, $s$; the thickness of the cover-layer, $t$; the porosity of the cover-layer, $p$; a measure of the roughness of the cover-layer, $r$; a measure of the shape of the armor units, $S$; and the packing and construction characteristics, $P$. There are probably other parameters that could be included in (1) to describe the face and the underlayers, but it is assumed that the variable $P$ includes all other effects.

The variables in (1) can be reduced in number by incorporating certain descriptors of the structure and the detailed characteristics of the breakwater units, e.g., $t, p, r, S$, and $P$, into one nondimensional parameter $\beta$. (It should be noted that (1) is being used to describe the incipient motion of armor units on a structure, so that no consideration is given at this point in the discussion to the percentage of damage suffered by the structure.) Therefore, the variable $\beta$ describes the shape and the interlocking features of the individual breakwater armor units as well as the overall geometric characteristics of the constructed breakwater. If it is assumed that the breakwater is not overtopped by waves, the vertical distance from the water surface to the crest of the structure, $d$, and width of the crest, $s$, are no longer important variables. Hence, (1) can be reduced to the following:

$$
f\left[H, T, h, 1 / m,\left(\rho_{s}-\rho_{w}\right), \rho_{w}, g, W, \mu, \alpha, \beta\right]=0 .
$$

In (2) there are eleven variables and, as there are three independent dimensions, eight dimensionless parameters should exist that characterize the problem. Choosing the depth, fluid density, and acceleration of gravity as repeating variables, one set of dimensionless parameters that can be constructed is:

$$
\phi\left(\frac{H}{h}, \frac{T^{2} g}{h}, \frac{\rho_{s}-\rho_{w}}{\rho_{w}}, \frac{W}{h^{3} \rho_{w} g}, \frac{\mu / \rho_{w}}{(g h)^{1 / 2} h}, \frac{1}{m}, \alpha, \beta\right)=0,
$$

where $\phi($ ) indicates "function of."

The second dimensionless variable in (3) is proportional to the ratio of the wave length to the depth, and the fifth parameter is the inverse of a Reynolds Number; the velocity used is the shallow-water wave celerity. By a suitable combination of terms in (3) it can be shown that the length in the Reynolds Number can be expressed as a characteristic dimension of an armor unit and the velocity can be expressed as the water-particle velocity. Thus, (3) can be rewritten as:

$$
\phi\left(\frac{H}{h}, \frac{L}{h}, \frac{\rho_{s}-\rho_{w}}{\rho_{w}}, \frac{W}{h^{3} \rho_{w} g}, \mathbf{R}, \frac{1}{m}, \alpha, \beta\right)=0,
$$

where $\mathbf{R}$ is the Reynolds Number. Since in general the surface of a rubble- 
mound is composed of large-scale roughnesses, during the run-up of waves on the structure the influence of the Reynolds Number in the region of maximum potential damage should be small and under certain conditions may be neglected. If waves that break offshore of the structure are not considered, then the offshore slope $1 / m$ is not significant; the primary effect of the offshore slope is to define the type of breaking wave, i.e. surging, plunging, collapsing, to which the seaward face of the structure is exposed. [Ahrens (1970) has shown that the form of the breaking wave on the structure may be an important aspect of stability, an effect discussed in Sect. 2.2.] For purposes of this discussion both the Reynolds Number and the offshore slope are eliminated from (4) yielding:

$$
\frac{W}{h^{3} \rho_{w} g}=\phi\left(\frac{H}{h}, \frac{L}{h}, \frac{\rho_{s}-\rho_{w}}{\rho_{w}}, \alpha, \beta\right) .
$$

Equation (5) states that, under the assumptions made, the weight of an armor unit that is marginally stable is a function of the relative wave height, relative wave length, submerged specific gravity of the armor material, angle of the breakwater with the horizontal, and a factor that pertains to the type of armor, breakwater configuration, and method of construction. [By combining the first and second terms on the right-hand side of (5), the nondimensional weight becomes a function of the wave steepness and the relative wave length along with the other variables.]

Numerous investigators, e.g. Iribarren \& Nogales (1953), Beaudevin (1955), Svee, Traetteberg \& T $\phi$ rum (1965), and Hudson (1958), to mention only a few, have developed, through analysis, experiments, and field observations, expressions for design purposes to describe the stability of breakwaters under wave attack. Selected experimental results from these and similar studies are described in detail in Sect. 2.2.

A development is presented to demonstrate how certain variables in (5) can be combined using physical arguments to provide an expression that describes the minimum weight of stable armor units for given wave conditions and rubble-mound configurations. Certain features of this development are based on an approach proposed by Hudson (1958). Figure 2 shows schematically an armor unit resting on a matrix of units on the face of an idealized breakwater; for convenience, the condition is considered where the wave has run up the face of the breakwater and the velocities and accelerations are now directed downslope. It is assumed that the forces acting on the unit are independent and consist of a drag force $F_{D}$, an inertial force $F_{I}$, and a lift force $F_{L}$ similar to the approach of Morison et al (1950) for wave forces on structures. The first two forces are assumed to act parallel to the breakwater face and the third perpendicular to the face. For simplicity, the forces are assumed to act at the center of gravity of the unit, although the following treatment would be modified only slightly by including additional variables for the points of application and the directions of the applied forces. Moments are taken about the point of contact (support) shown in Figure 2, resulting in

$$
\left(F_{D}+F_{l}\right) c_{1} l \cos \theta+F_{L} c_{1} l \sin \theta=\left(\rho_{s}-\rho_{w}\right) g c_{1} c_{3} l^{4} \sin (\theta-\alpha),
$$


where

$$
\begin{aligned}
& F_{\mathrm{D}}=\frac{\rho_{w}}{2} C_{D}\left(c_{2} l^{2}\right) u|u|, \\
& F_{I}=\rho_{w} C_{M}\left(c_{3} l^{3}\right)(d u / d t), \\
& F_{L}=\frac{\rho_{w}}{2} C_{L}\left(c_{2} l^{2}\right) u^{2},
\end{aligned}
$$

and $C_{D}, C_{L}$, and $C_{M}$ are the drag coefficient, the lift coefficient, and the virtual-mass coefficient, respectively; $\theta$ is the angle of repose of the material, $l$ is a convenient length dimension of the armor unit, and $c_{i}$ is a constant of proportionality such that $c_{1} l$ is the distance from the point of support to the center of gravity of the unit, $c_{2} l^{2}$ gives the cross-section area of the unit in a direction perpendicular to the direction of the velocity, and $c_{3} l^{3}$ gives the volume of the unit. Hudson (1958) neglects the lift and inertia forces in his development, but emphasizes that this does not imply these forces are unimportant. If one neglects these forces, $(6)$ can be rewritten as

$$
u^{2}=2\left[\frac{\rho_{s}-\rho_{w}}{\rho_{w}}\right] \frac{g}{C_{D}}\left[\frac{c_{3}}{c_{2}}\right] l \frac{\sin (\theta-\alpha)}{\cos \theta} .
$$

The problem proposed by Hudson (1958) is for the case of short-period waves that do not break before reaching the structure, but may break on the structure. He assumed that the water particle velocity $u$ at the point of breaking on the structure (where the depth is $h_{b}$ ) is equal to the wave celerity, 'taken to be $\left(g h_{b}\right)^{1 / 2}$, the usual expression for small-amplitude long-period waves. In addition, the wave height at breaking, $H_{b}$, is assumed to be proportional to the depth. These three assumptions imply that $u^{2} \propto g H_{b}$. Hudson further assumes that the forces tending to displace armor units due to breaking and nonbreaking waves would be of the same order of magnitude; hence $u^{2}=g H / \kappa$ where $\kappa$ is a coefficient that may be a function of the characteristics both of the wave system offshore and of the structure. (It is apparent that elements of these assumptions could be discussed in some detail; however, this will not be done here.) Therefore, (7) can be rewritten as:

$$
H=\left[\frac{2 \kappa c_{3}{ }^{2 / 3}}{C_{D} c_{2}}\right]\left(S_{s}-1\right)\left[\frac{W}{\gamma_{s}}\right]^{1 / 3} \frac{\sin (\theta-\alpha)}{\cos \theta},
$$

where $\gamma_{s}$ is the specific weight of the armor units and is equal to the product of the density $\rho_{s}$ and the accelcration of gravity $g$, and $S_{s}=\rho_{s} / \rho_{w}$ is the specific gravity of the units. From the definition

$$
\Delta^{1 / 3} \equiv \frac{2 \kappa c_{3}^{2 / 3}}{C_{D} c_{2}}
$$

(8) can be rearranged to yield

$$
\frac{\gamma_{s}^{1 / 3} H}{\left(S_{s}-1\right) W^{1 / 3}}=\Delta^{1 / 3}(\tan \theta \cos \alpha-\sin \alpha) \equiv N_{s},
$$


where the parameter $N_{s}$ is defined as the stability number for the breakwater. With reference to (9) [and (4)] the variable $\Delta$ shouid be a function

$$
\Delta=f\left(\frac{H}{h}, \frac{L}{h}, \mathbf{R}, \frac{1}{m}, \alpha, \beta\right)
$$

or for the reduced list of variables in (5)

$$
\Delta=f\left(\frac{H}{h}, \frac{L}{h}, \alpha, \beta\right) .
$$

It should be noted that $\beta$ includes the effect on stability of the specific characteristics of the breakwater design, construction, and of the shape and packing of the individual units.

Employing (10), or a variation of this expression, numerous investigators have proposed relationships for the minimum stable weight of a rubble-mound armor unit for given wave conditions, the most frequently used being those proposed by Hudson (1958), Iribarren [see Iribarren \& Nogales (1953) and Iribarren (1965)], and Svee, Traetteberg \& Tф̆rum (1965):

$$
\begin{array}{ll}
\text { Hudson: } & W=\frac{\gamma_{s} H^{3}}{K_{D}\left(S_{s}-1\right)^{3} \cot \alpha} \\
\text { Iribarren: } \quad W=\frac{N \gamma_{s} H^{3}}{\left(S_{s}-1\right)^{3}(\tan \theta \cos \alpha-\sin \alpha)^{3}} \\
\text { Svee et a1: } \quad W=\frac{K \gamma_{s} H^{3}}{\left(S_{s}-1\right)^{3}(\cos \alpha)^{3}}
\end{array}
$$

where $K_{D}, N$, and $K$ are called the stability factors.

It is interesting to note the similarities among (12a), (12b), and (12c): the form of $(10)$ is followed in each case except for the manner in which the slope of the face of the structure and the angle of repose (or the coefficient of friction between armor units) are included. In (12b) the relation between the angle of repose and the angle of the face of the structure is the same as that obtained from physical arguments (10); in (12a) and (12c) the stability factors $K_{D}$ and $K$ both must be functions of the coefficient of friction between units. It is interesting to note that the relative wave length, the Reynolds Number, and the offshore slope [see (11a)] are not included directly in any of the expressions shown. Hence, these effects also must be incorporated in the stability coefficients if they are important. [To some extent an effect of Reynolds Number not included explicitly in (12) is present, since (8) and (9) show that the stability factor is dependent on a drag coefficient, $C_{D}$.] In addition, where the inertial forces and lift forces were neglected in the development of $(10)$, these forces must in some way affect the stability factors in (12). Therefore it appears that even though the general arrangement of terms in (12) appears reasonable, the absence of certain other variables implied from dimensional analysis and other arguments indicates that experiments should be conducted to determine both the shape of the structure and the acceptable size of armor units to resist damage from a given wave system. The experiments would be guided by analyses similar to those presented here. 


\subsection{Experimental Considerations}

The experimental results presented in this section were selected from a number of sources and are used to demonstrate certain features of the analyses described in Sect. 2.1. In some cases these data were obtained in the process of designing particular structures; however, an attempt also has been made to use the results of experiments that were more general.

Hudson (1958) presents the results of an extensive series of experiments conducted to obtain basic information on the stability of rubble-mound breakwaters [see also Hudson \& Jackson (1953), Hudson (1959), and Hudson \& Jackson (1959)]. Certain initial studies were conducted to determine the angle of repose of modeled breakwater armor to permit evaluation of the stability coefficient $N$ in Iribarren's expression (12b). Three different weights of quarry-stone were used along with concrete cubes and concrete tetrapods. The angle of repose was determined for cases where the material had been dumped in water, dumped in air, stacked in water, and stacked in air. For the quarry-stone the value of $\tan \theta$ varied from a minimum of 0.78 to a maximum of 1.28 with an average value of approximately 0.98 . Considering all of the material, the angle of repose varied with both the shape of the armor units and method of placement; in addition, there was a considerable scatter from experiment to experiment. Subsequently, Iribarren (1965) carefully measured the angle of repose for quarry-stone of three different sizes, cubes, and tetrapods (each of two different sizes) and found that the angle of repose for each material was a function of the number of units and was independent of the absolute size of the particular armor. For all materials tested,

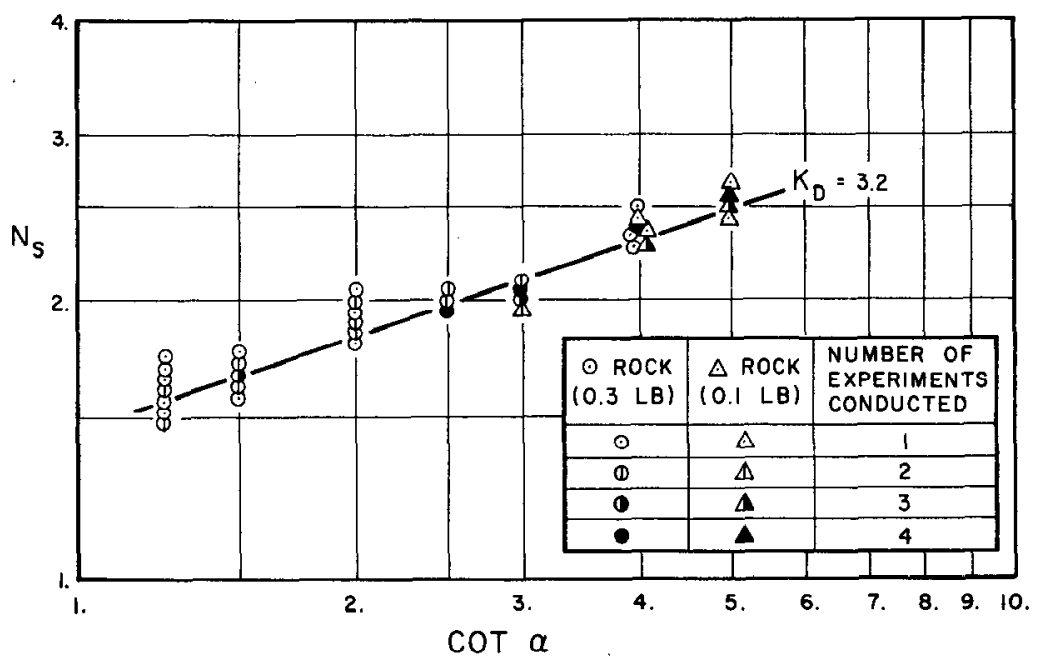

Figure 3 Stability of quarry-stone armor for no-damage and no-overtopping (Hudson, 1958). 
the tangent of the angle of repose varied from about 3.0 for 5 units to between 1.0 and 1.5 for 50 units.

Primarily because of problems associated with determining the angle of repose of the rubble-mound material, Hudson (1958) experimentally defined the stability number $N_{s}$ in (10) in terms of the angle of the slope, $\alpha$, and the characteristics of the structure and the armor material, $\beta$. Laboratory experiments were conducted in a wave tank using regular waves, with the model breakwater exposed to a burst of waves for a period of time such that waves incident upon the structure were not reinforced by waves reflected from the wave generator. Thus the height of the waves to which the structure was exposed could be determined from a calibration of the wave tank without the structure in place; the wave height used in (12a) is defined in this way. [Others have shown that the presence of the structure affects the height of the maximum incident wave at a structure, for example, see Danel (1952), so attention must be given to its definition.]

For a rubble-mound composed of quarry-stone a basic breakwater cross section was tested under the condition of no overtopping by waves with various heights. The slope of the seaward face of the structure was varied and experiments were repeated for reproducibility of results; in this way for a given structure the wave height which gave a spccificd percentage of damage was determined. Therefore, referring to (10), the value of the stability number $N_{s}$ was evaluated as a function of the breakwater slope, $\alpha$, for a given armor-layer material. The results of these experiments using quarry-stone are presented in Figure 3 for the condition of no damage where the abscissa is the cotangent of the angle of the seaward face to the horizontal and the ordinate is the stability number $N_{s}$. The data are somewhat scattered, but the trend is obvious: the stability coefficient $N_{s}$ appears proportional to $(\cot \alpha)^{1 / 3}$. The constant of proportionality is the parameter $K_{D}$ that appears in (12a); and for this quarry-stone $K_{D}=3.2$. Within the reproducibility of the experiments, the same relationship was obtained with stone of a different nominal size.

Since, as shown in (11a) or (11b), the stability coefficient $K_{D}$ is a function of $\beta$, which also could include the allowable percentage of damage, the value of $K_{D}$ varies with percentage of damage. Results that relate to the percentage of damage are presented in Figure 4 with the stability number $N_{s}$ plotted as a function of $\cot \alpha$. Although the data are scattered, the same functional relationship is apparent as in Figure 3 with $N_{s}$ proportional to $(\cot \alpha)^{1 / 3}$. For an acceptable damage of 10 to $20 \%$, the value of $K_{D}$ is approximately three times that for zero damage, which indicates that the weight of the armor could be reduced nearly $70 \%$ for the same wave conditions and structure and armor characteristics.

In the fundamental experiments conducted by Hudson (1958) the relative depth $h / L$ varied from 0.1 to 0.5 and the ratio of wave height to depth varied from approximately 0.14 to 0.5 . Therefore, two important cases were not investigated: shallow-water waves and waves breaking just seaward of the structure. [These have been investigated by Hudson as well as others in connection with specific designs, but these studies will not be treated here due to their more applied nature; see also, for example, Vanoni \& Raichlen (1966).] Because of the limited variation of 


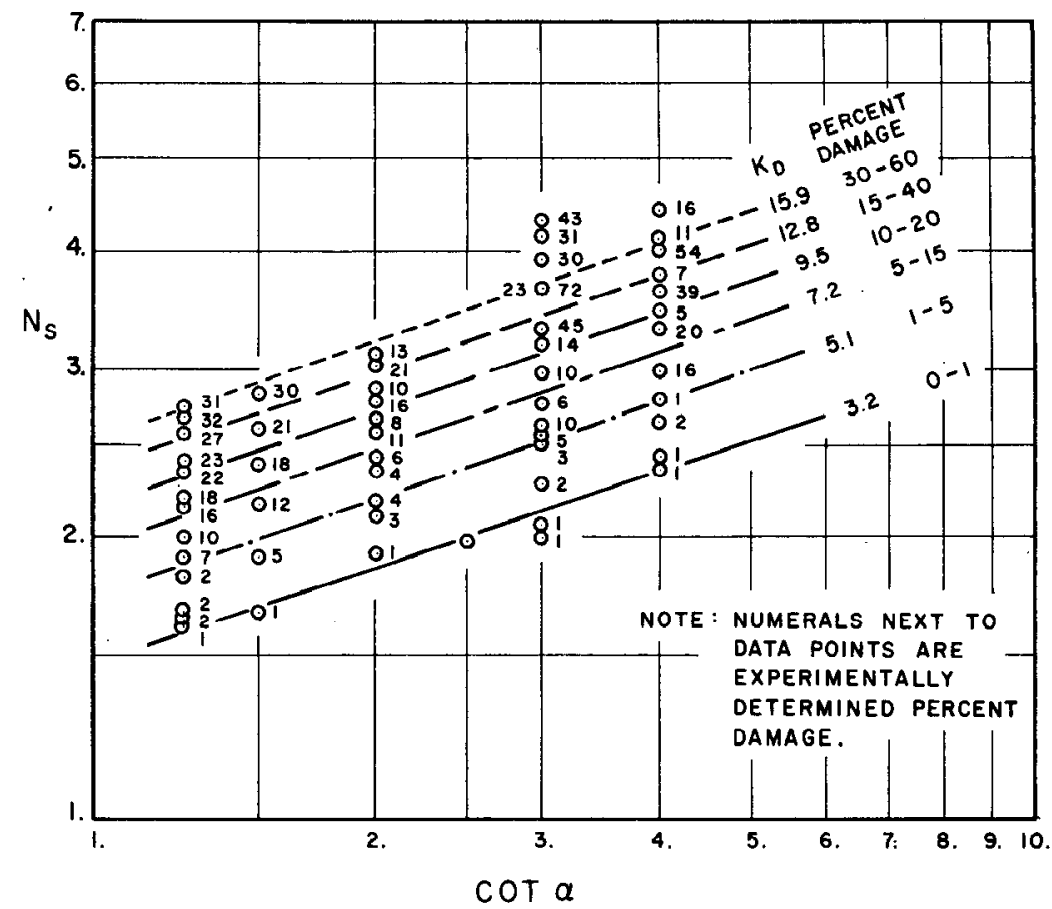

Figure 4 Stability of quarry-stone armor as a function of percentage of damage (Hudson, 1958).

the ratio of depth to wave length in these experiments it is difficult to draw conclusions about the importance of this variable. However, Brandtzaeg (1965), in summarizing the work of several authors [Svee, Traetteberg \& Torum (1965), Iribarren (1965), Saville, Garcia \& Lee (1965)], comments that the effect of the ratio of depth to wave length on the stability of a rubble-mound structure appears small. Certain problems associated with breaking waves will be discussed later. It appears that extensions of this fundamental work by Hudson (1958) to investigate in detail the effect of long waves and breaking waves on the stability of a structure are indicated.

The ability of armor units on the face of a breakwater to interlock is quite important with respect to stability, and cssentially this interlocking is described by the importance of the parameter $\beta$ in $(11 \mathrm{a}, \mathrm{b})$. Quarry-stone has a limited ability to interlock; generally interlocking improves as the material becomes more angular. However, specially shaped concrete armor units, some of which were mentioned in Sect. 1, are designed to interlock and thus reduce the required weight of the stable units. Over the years many different shapes of concrete armor units have been developed, and experiments similar to those of Hudson (1958) have been performed to evaluate the stability of such units. (It should be realized that the 
stability of the structure is also a function of specific features of the structure such as the cross section, so care must be taken in applying the results of one experiment to another design.)

Merrifield \& Zwamborn (1966) present the results of experiments conducted in connection with the development of breakwater units termed dolosse. In these experiments the stability factor, $K_{D}$, was evaluated as a function of the percentage of damage for one particular slope $(\cot \alpha=1.5)$ and design of the underlayers of the structure. The experiments were conducted with regular waves in a wave tank in a manner similar to those conducted by Hudson (1958). These results are shown in Figure 5 with the stability factor $K_{D}$ plotted as a function of the percentage

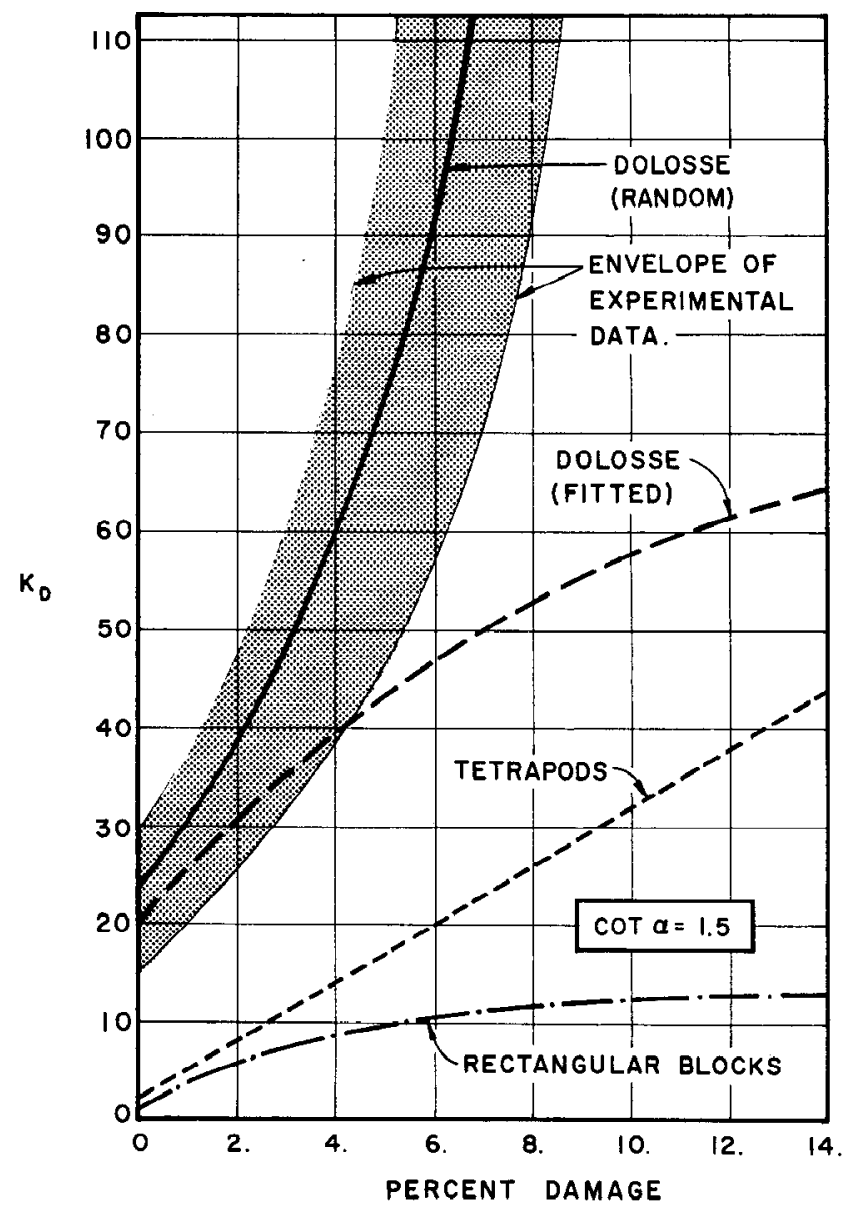

Figure 5 Stability of several types of armor as a function of percentage of damage (Merrifield \& Zwamborn, 1966). 
of damage, which was assessed in terms of movement of a unit over a specific distance as well as of excessive rocking of the unit that in the prototype could cause destruction of that unit. These experiments are particularly interesting because they show a comparison of different types of armor units with similar underlayers under comparable test conditions. For damage less than $5 \%$ the stability factor increases by a factor of about five for randomly placed dolosse compared to tetrapods or rectangular blocks. From (12a) this increase in the stability factor corresponds to a comparable decrease in the weight of the unit required, for other variables kept constant. A significant difference in stability is noted in Figure 5 for randomly placed dolosse compared to the units packed (or fitted). For the former the structure appears to become more stable with increasing damage, which indicates that the dolosse become more interlocked as damage increases, but for the packed dolosse the opposite is true. At zero damage the stability factor for the dolosse (either randomly placed or packed) is approximately six times that determined by Hudson (1958) for quarry-stone (see. Figure 3), which means dolosse with onesixth the weight of quarry-stone afford the same protection for the same wave

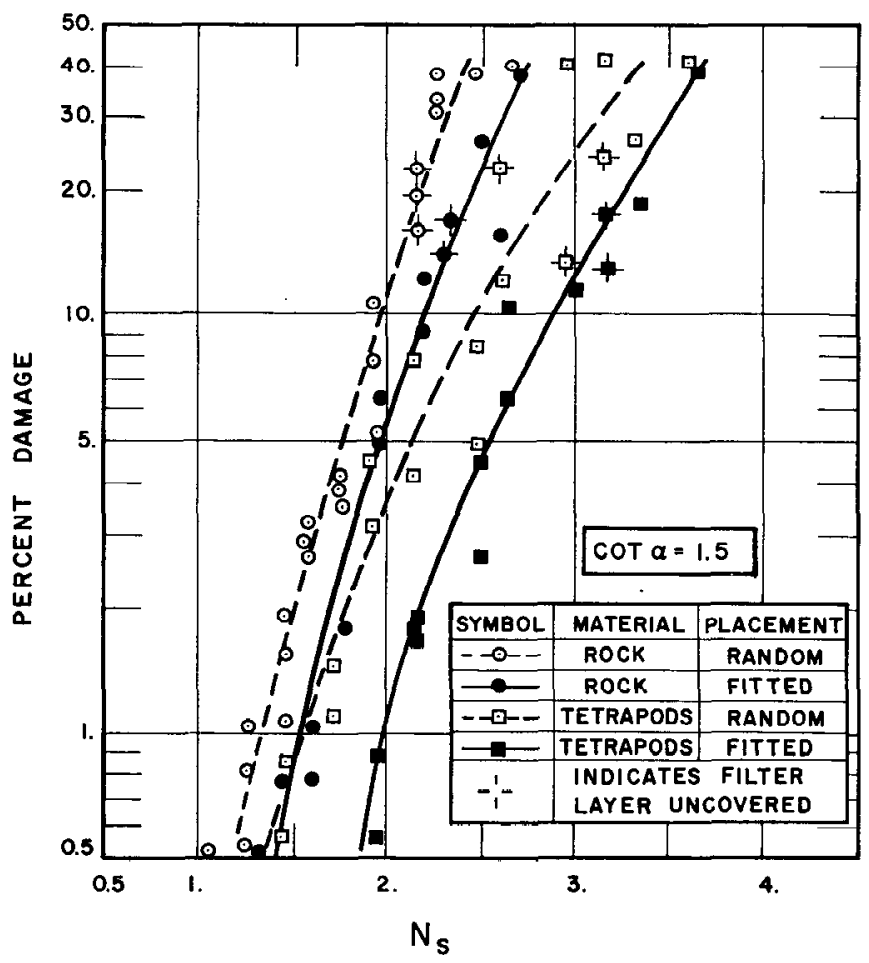

Figure 6 Stability of quarry-stone and tetrapod armor as a function of pcrcentage of damagc for two techniques of placement (Font. 1970). 
conditions, structure shape, and density of units. (These results are meant to indicate only the effect of shape of armor units on stability and do not constitute design criteria.)

It is evident from certain of the results discussed that the packing and method of construction [included in the parameter $\beta$ in $(11 \mathrm{a}, \mathrm{b})$ ] have an important effect on stability. Recent work by Font (1970) demonstrates this aspect of the stability problem quite well. Some results relative to this are shown in Figure 6, where the stability of a breakwater $(\cot \alpha=1.5)$ armored with two different types of material was studied. For each of these materials, quarry-stone and tetrapods, two different methods of placement were used: randomly placed without attempting to interlock units, and carefully fitted units forming a well interlocked layer. In Figure 6 the stability number $N_{s}$ is shown as a function of damage observed: as the percentage of damage increases the stability number increases for each of the four cases investigated. The structure was built with an impermeable core and two or three layers of filter material with the armor units above. Therefore, as damage increased to about $15 \%$ the filter layer was uncovered in some experiments. With both rock and tetrapods it was found, for a given percentage of damage, that higher waves were necessary to cause this damage, that is, a larger value of $N_{s}$, when the material was carefully fitted compared to random placement. Hence, these results indicate for given wave conditions that a smaller armor unit is acceptable when careful placement techniques are used. [Note for dolosse shown in Figure 5 the opposite was found, which may be a peculiarity of the dolos shape. For quarry-stone Kidby, Powell \& Roberts (1964) found that careful fitting of angular rock above the mean water level with the long axis placed perpendicular to the face of the structure yielded a significantly more stable structure than that composed of the same material randomly placed.] In addition, Font (1970) found that the maximum observed damage occurred near the intersection of the mean water level with the breakwater face and generally was concentrated in a region approximately two wave heights above and below that point.

In an earlier study, Font (1968) investigated the effect of storm duration on structure damage, that is, duration of exposure to waves of a particular height. A portion of these data are presented in Figure 7 where the abscissa is the wave height that caused the percentage of damage indicated on the ordinate normalized by the wave height that caused $1 \%$ damage. Data are presented for breakwaters composed of three sizes of quarry-stone and for the structure exposed to 500 waves and to 3000 waves. Where great damage occurred, the damage generally increased as the duration of exposure increased. However, where little damage occurred, data show more damage for shorter duration of wave exposure, which indicates that the shorter exposure may improve the interlocking, creating a structure more resistent to longer exposure of the same wave.

As mentioned previously, both the relative wave length $L / h$ and the offshore slope $1 / \mathrm{m}$, are important parameters in defining stability when the structure is exposed to breaking long waves. Galvin (1968) has shown that these variables, along with the relative wave height $H / h$, generally determine the shape of the breaking wave to which a structure is exposed. A series of experiments were 


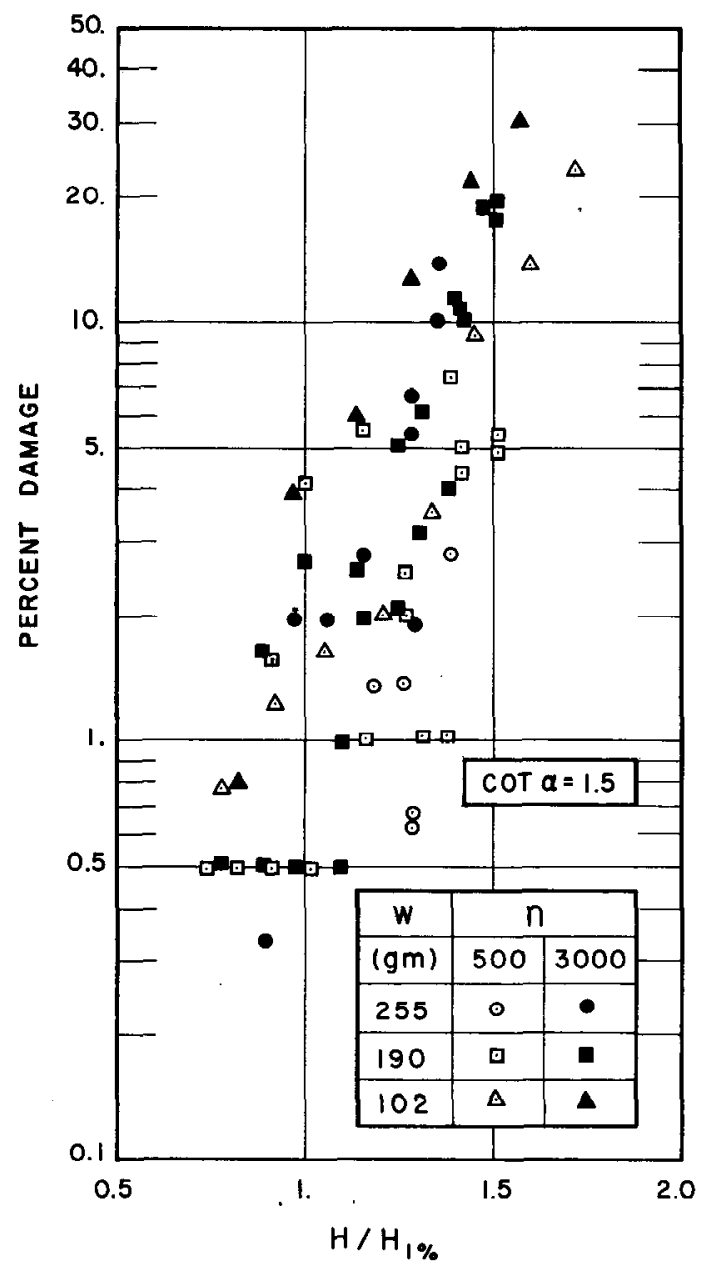

Figure 7 Percentage of damage for various storm durations (Font 1968).

conducted by Ahrens (1970) to investigate this effect on the stability of a structure. In these experiments the rubble-mound was built of quarry-stone to a large scale with a slope of $1: 1.25(\cot \alpha=1.25)$ in a wave tank with a horizontal bottom. This structure was exposed to waves with a maximum ratio of wave height to depth of 0.23 . so that these waves broke on the face of the structure and not before reaching the structure. The types of breakers on the structure ranged from surging breakers to plunging breakers, with a portion of the experiments producing the collapsing breaker defined by Galvin (1968). It was found that the stability number $N_{s}$ decreased by about $40 \%$ for the case of the collapsing breakers compared 
to either surging or plunging breakers for the condition of no damage. It should be emphasized that in these experiments the breaker shape was defined by the structure, not by offshore conditions. Nevertheless, since breaker shape appears important in defining stability, the relative wave length, $L / h$, and the offshore slope, $1 / \mathrm{m}$, may be important for breaking waves. Certainly additional fundamental investigations are warranted to investigate this feature of stability.

Limited experiments have been conducted in the laboratory by Dai \& Kamel (1969) to investigate the effect of Reynolds Number on the stability number. Rubblemound structures composed of quarry-stone and of quadripods were constructed at three different model scales: $L_{r}=1 / 2,1$, and 7.5 , where $L_{r}$ is the ratio of a length in the model to the corresponding length in the prototype. In all cases an attempt was made to build the structure the same way for each of the three scales. To some extent surface texture was also considered. For example, the rough surface texture of the structure for quarry-stone was due to the use of angular rock, whereas a smoother surface resulted when the rock was rounded; two different methods of casting were used for the quadripods to produce a smooth and a rough unit. Selected data are presented in Figure 8 where the stability number $N_{s}$ is plotted as a function of the model scale for each of four cases; the corresponding ratio of the depth to wave length is also indicated for the data. The Reynolds Number is defined in terms of a characteristic length of an armor unit and a theoretical velocity parallel to the slope near the still-water-level; the Reynolds Number varied from $10^{4}$ for the smallest scale to $10^{5}$ to $10^{6}$ for the largest scale for these experiments. Although the data are scattered the stability number appears to decrease with decreasing model size or Reynolds Number, and there is an apparent effect of the ratio of depth to wave length on the stability number for a given model scale. Although these tests are not conclusive, and more effort should be directed to this aspect of the problem, the data demonstrate that the choice of scale for an experiment in this type of investigation is as important as it is in other experiments where gravity forces are dominant.

Only limited data are available from stability investigations using irregular (nonperiodic) waves. It has been generally assumed that stability experiments conducted in the laboratory with regular wave systems, where the wave height was set equal to the significant wave height of an irregular wave train, would yield conservative results compared to testing with the actual irregular wave train, although from the results available this assumption may not be completely valid. (The significant wave is defined as the average of the highest one-third of the wave train.)

Studies have been conducted using wind-generated waves in the laboratory [see, for example, Nagai (1962), Plate \& Nath (1969)], but the reproduction of a scaled ocean-wave spectrum in a laboratory wave tank using wind alone is difficult. Significant advances are being made in irregular wave studies using mechanical wave generators in the laboratory that are hydraulically driven and controlled by a programmed servomechanism. Carstens, T $\phi$ rum, \& Traetteberg (1966) present results of a stability study of a rubble-mound armored with quarry-stone in a wave tank equipped with a mechanical irregular-wave generator. Two different structure slopes were examined ( $\cot \alpha=1.25$ and 1.5$)$, but only selected results are 


\section{2}

\section{RAICHLEN}

presented here. The structure was exposed to two wave spectra in separate experiments: the Berlevåg $(\mathrm{B})$ spectrum and the model Neumann $(\mathrm{N})$ spectrum. These spectra are shown in Figure 9, and it is apparent that the B spectrum has energy concentrated in a frequency band narrower than the $\mathrm{N}$ spectrum, although for the same significant wave height the frequency distribution of wave heights for these two spectra were similar. Hence, if indeed the stability is a

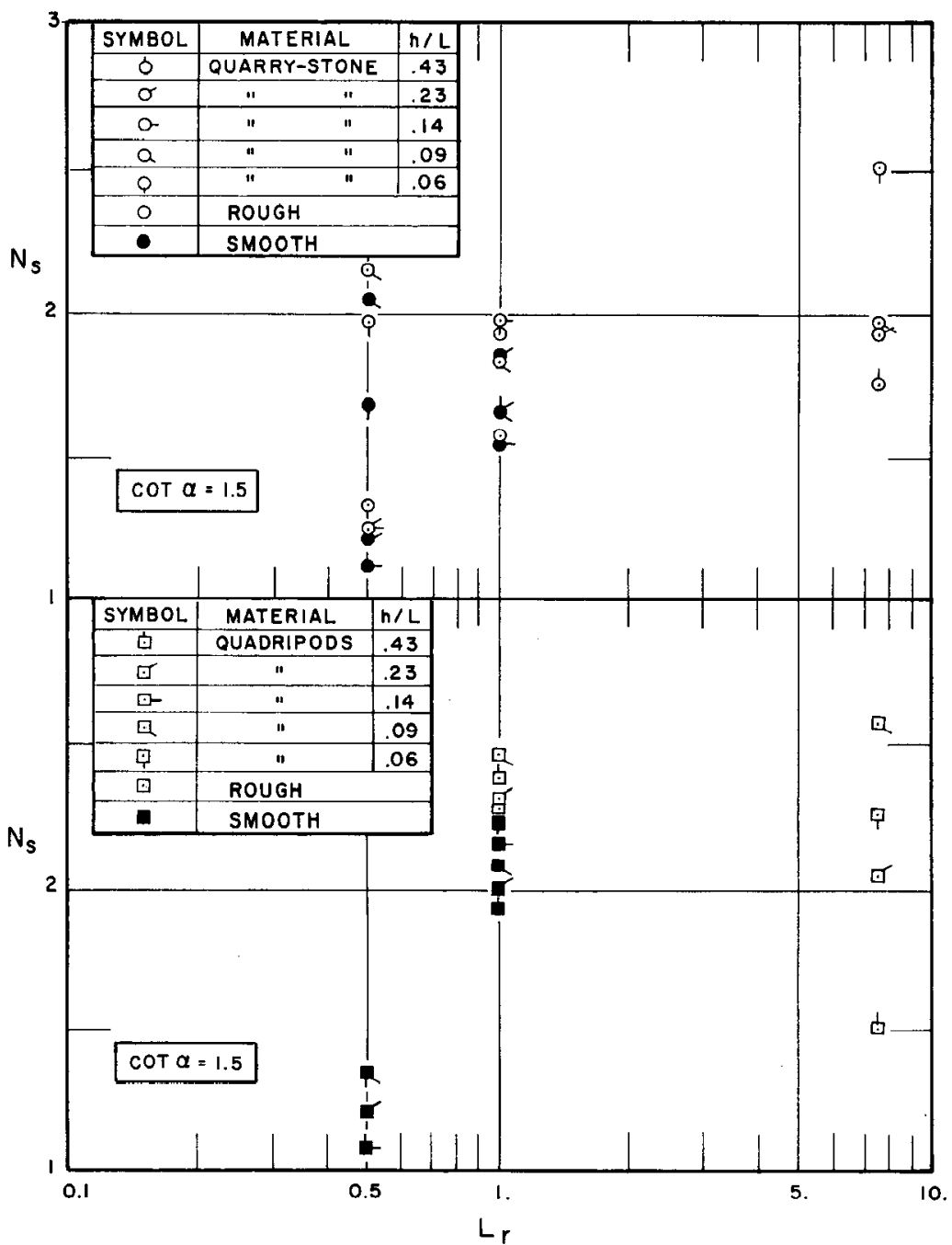

Figure 8 Effect of model scale on stability; quarry-stone and quadripods (Dai \& Kamel, 1969). 


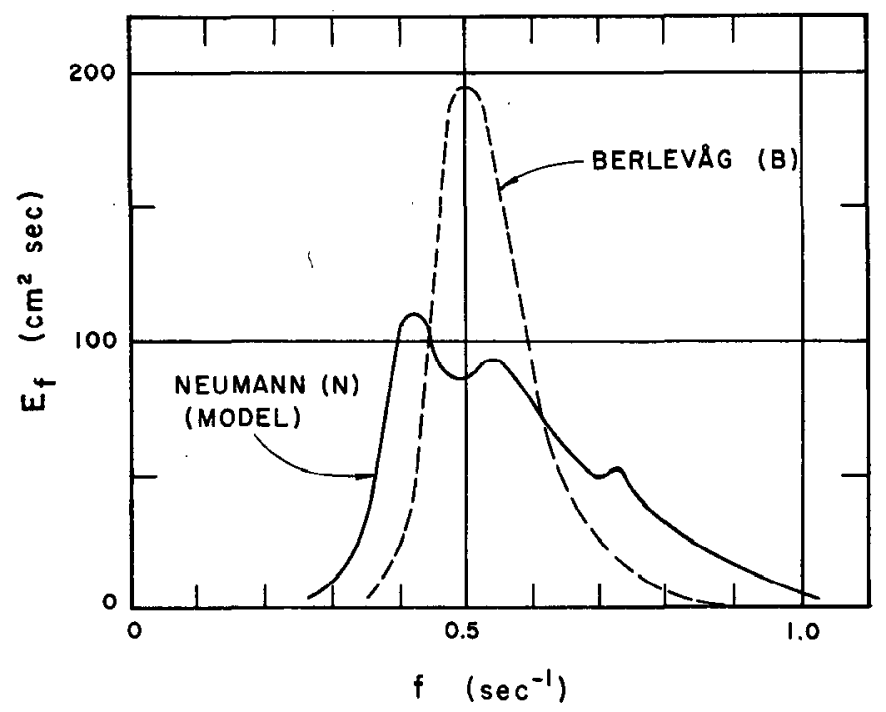

Figure 9 Model wave spectra (Carstens, T $\phi$ rum \& Traetteberg, 1966).

function of the frequency distribution of energy, differences would be expected between the results of the stability tests when the structure is exposed to these spectra. For comparison, the structure also was exposed to regular waves with a wave height approximately the same as the significant wave height associated with the irregular waves.

In the experiments the structure was exposed to irregular waves with a given frequency-energy content for a period of time and then the energy was increased by the same percentage at all frequencies, with the damage observed each time the energy content of the wave system was increased. This is different from an ocean-wave spectrum that grows in energy content with increased wind duration from the high frequency end with the low-frequency energy content increasing with increasing significant wave height.

Selected results of these experiments for the structure with the steeper slope ( $\cot \alpha=1.25$ ) are presented in Figure 10, where the percentage of damage is shown as a function of the significant wave height for irregular waves and as a function of the wave height for regular waves. (The model was exposed to the waves in 15 min increments.) The differences between the wave heights that cause the same damage using the Berlevåg spectrum or a regular wave train are small, as would be expected from the spectral shape shown in Figure 9. However, a larger significant wave is required when using the Neumann spectrum for nearly all percentages of damage. For less than $2 \%$ damage it is difficult to distinguish among the results with either regular or irregular waves (Figure 10). These data are revealing and indicate a need for additional experimental effort using input wave spectra before definite conclusions may be drawn with regard to the relation of results 


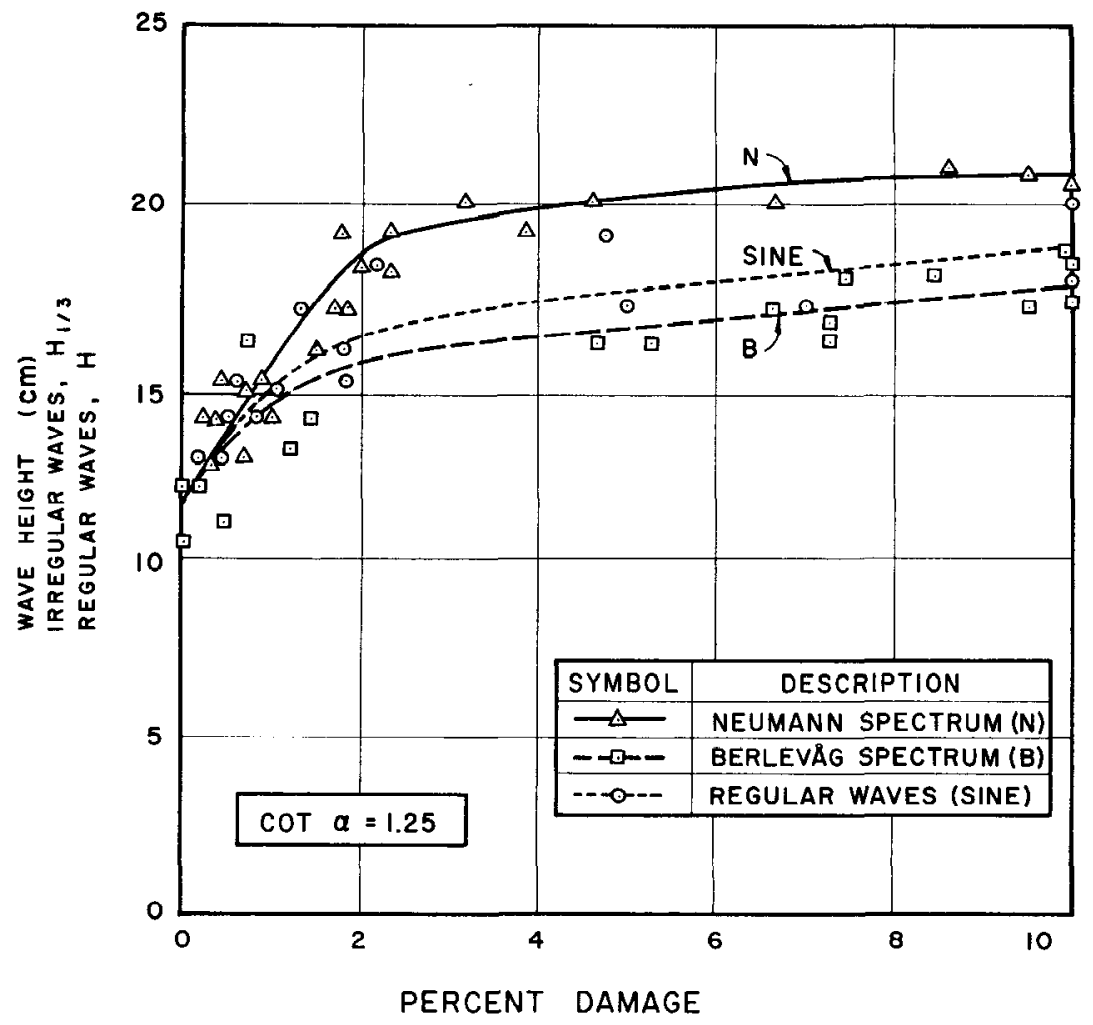

Figure 10 Percentage of damage as a function of wave height (Carstens, Tọrum \& Traetteberg, 1966).

obtained with regular waves compared with the expected damage due to irregular waves.

In the United States the organization responsible for the review of most designs dealing with coastal structures is the U.S. Army Corps of Engineers. Through one of its laboratories, the Coastal Engineering Research Center (CERC), suggested values of the stability factor $K_{D}$ to be used in (12a) for various materials and conditions of exposure have been collected and are presented in Table 1 (CERC, 1966). Conditions are shown in Table 1 for breaking and nonbreaking waves for the trunk of the structure as well as the terminus (the head). These results have been gathered from many different experiments and prototype observations. For no damage it is interesting to note that the type of material, placement, and thickness of the cover layer influence the stability factor, and because of threedimensional effects larger units are necessary at the end of the breakwater for the same degree of stability compared to the trunk of the structure. [Recommendations for modifications to these values have recently been presented by Hudson (1974).] 
Table 1 The stability factor $K_{D}$ in (12a) for determining armor unit weight for no-damage criteria (CERC, 1966)

\begin{tabular}{|c|c|c|c|c|c|c|}
\hline \multirow[b]{2}{*}{ Armor Units } & \multirow[b]{2}{*}{$n^{\mathrm{a}}$} & \multirow[b]{2}{*}{ Placement } & \multicolumn{2}{|c|}{ Structure Trunk } & \multicolumn{2}{|c|}{ Structure Head } \\
\hline & & & $\begin{array}{l}\text { Breaking } \\
\text { Wave }^{\mathrm{b}}\end{array}$ & $\begin{array}{l}\text { Nonbreaking } \\
\text { Wave }^{c}\end{array}$ & $\begin{array}{l}\text { Breaking } \\
\text { Wave }^{b}\end{array}$ & $\begin{array}{c}\text { Nonbreaking } \\
\text { Wave }^{c}\end{array}$ \\
\hline $\begin{array}{l}\text { Smooth rounded } \\
\text { quarry-stone }\end{array}$ & 2 & random & 2.5 & 2.6 & 2.0 & 2.4 \\
\hline $\begin{array}{l}\text { Smooth rounded } \\
\text { quarry-stone }\end{array}$ & $>3$ & random & 3.0 & 3.2 & - & 2.9 \\
\hline $\begin{array}{l}\text { Rough angular } \\
\text { quarry-stone }\end{array}$ & 1 & random & 2.3 & 2.9 & 2.0 & 2.3 \\
\hline $\begin{array}{r}\text { Rough angular } \\
\text { quarry-stone }\end{array}$ & 2 & random & 3.0 & 3.5 & 2.7 & 2.9 \\
\hline $\begin{array}{r}\text { Rough angular } \\
\text { quarry-stone }\end{array}$ & $>3$ & random & 4.0 & 4.3 & - & 3.8 \\
\hline $\begin{array}{r}\text { Rough angular } \\
\text { quarry-stone }\end{array}$ & 2 & special $^{\mathrm{d}}$ & 5.0 & 5.5 & 3.5 & 4.5 \\
\hline Modified cube & 2 & random & 7.0 & 7.5 & - & 5.0 \\
\hline Tetrapod & 2 & random & 7.5 & 8.5 & 5.0 & 6.5 \\
\hline Quadripod & 2 & random & 7.5 & 8.5 & 5.0 & 6.5 \\
\hline Hexapod & 2 & random & 8.5 & 9.0 & 5.0 & 7.0 \\
\hline Tribar & 2 & random & 8.5 & 10.0 & 5.0 & 7.5 \\
\hline Tribar & 1 & uniform & 12.0 & 15.0 & 7.5 & 9.5 \\
\hline
\end{tabular}

${ }^{a} n$ is the number of units comprising the thickness of the armor layer.

${ }^{b}$ Minor-overtopping criteria.

c No-overtopping criteria.

${ }^{\mathrm{d}}$ Refers to special placement with long axis of stone placed normal to structure face.

\section{RUN-UP}

\subsection{Analytical Considerations}

Run-up is defined as the maximum vertical distance from the still-water surface to the position on the breakwater face to which the water surface rises during wave attack (see Figure 1). In this section the elevation of the crest of the rubblemound is assumed to be sufficient to prevent overtopping of the structure by waves; hence, the discussion is limited to considerations of run-up on the seaward face of the breakwater.

Similar to the case of breakwater stability, the problem of run-up is not amenable to a complete analytic treatment. Therefore, dimensional analysis again is used to define the important nondimensional parameters that describe the problem. If a functional relationship exists between the run-up and the description of the wave system and the structure for the condition of regular waves impinging at normal incidence on a breakwater face, this relationship can be expressed as:

$$
f\left(H, T, h, 1 / m, R, \rho_{w}, \mu, g, \alpha, \psi\right)=0,
$$

where, as before, $f($ ) indicates "function of." 


\section{RAICHLEN}

The first four variables of (13) define the incident-wave characteristics; the next term, $R$, is the run-up on the structure face measured vertically from the stillwater level; the next two terms define the fluid density $\rho_{w}$ and the dynamic fluid viscosity $\mu ; g$ is the acceleration of gravity; and $\alpha$ is the slope of the face of the structure with respect to horizontal. The last variable, $\psi$, describes the physical characteristics of the breakwater face which affect run-up, and would be a function of such factors as shape of the armor units, roughness of the face, permeability of the armor layer, characteristics of the underlying material, and method and type of construction. Hence, $\psi$ essentially describes various particular features of the breakwater and demonstrates the difficulty of developing universal run-up characteristics for rubble-mounds. The variables $\rho_{w}, g$, and $h$ are used in nondimensionalizing (13), resulting in the following:

$$
f\left(\frac{H}{h}, \frac{T^{2} g}{h}, \frac{1}{m}, \frac{R}{h}, \frac{\mu / \rho_{w}}{(g h)^{1 / 2} h}, \alpha, \psi\right)=0 .
$$

Equation 14 basically has the same type of terms as (3) did for stability considerations. By suitable combination of nondimensional variables, (14) can be rewritten:

$$
\frac{R}{H}=\phi\left(\frac{H}{h}, \frac{L}{h}, \frac{1}{m}, \mathbf{R}, \alpha, \psi\right),
$$

where the Reynolds Number, $\mathbf{R}$, is a function of the water-particle velocity and a linear dimension of the armor.

In (15) the relative run-up (expressed as the run-up elevation divided by the wave height) is a function of the wave characteristics as embodied in the ratio of wave height to depth and the ratio of the wave length to the depth as well as the offshore slope, $1 / \mathrm{m}$. (These three parameters define the characteristics of long waves and the latter becomes most important at breaking in defining the shape of the breaking waves. As before, for short waves, the first two terms can be combined to give a wave steepness and wave-length to depth ratio.)

The breakwater face, composed of rock or armor units, represents an hydrodynamically rough surface, and, for a sufficiently large Reynolds Number, the effect of the Reynolds Number on run-up as shown in (15) is minimal. Therefore, the list of variables shown in (15) can be reduced to:

$$
\frac{R}{H}=\phi\left(\frac{H}{h}, \frac{L}{h}, \frac{1}{m}, \alpha, \psi\right) .
$$

In conducting laboratory experiments to investigate run-up, if the scale of the experiments is not large enough, corrections for the effect of Reynolds Number must be applied to the results. Such corrections will be discussed briefly later.

\subsection{Experimental Considerations}

The variable $\psi$ in (16) embodies numerous characteristics of the rubble-mound that may in part be peculiar to a particular design, and for this reason laboratory experiments are conducted to evaluate run-up in the design of important structures. 
In this section selected experimental results from different investigations are used to describe the important features of run-up.

Figure 11 shows run-up data (CERC, 1966) for smooth and rubble-mound slopes; from Saville (1956) and Hudson (1958), respectively, and in both cases only experimental curves are shown without the corresponding data. The run-up is normalized with respect to the deep water wave height, $H_{0}$, and is plotted as a function of the ratio of the deep water wave height to the wave period squared, $H_{0} / T^{2}$; hence, the abscissa is proportional to the deep-water wave steepness. (The deep-water wave height is determined from small amplitude wave theory for shoaling from the measured wave height, depth, and wave period.) Attention is first directed toward the data for run-up on smooth slopes where the experiments were conducted with a $1: 10$ bottom slope leading seaward from the toe of the structure. The results are shown for various structure slopes with $1.25<\cot \alpha<5$, and in all cases the ratio of the deep-water wave height to the depth at the toe of the structure was less than 0.33. [With reference to (16), this method of data presentation assumes that the ratio of wave length to depth is relatively unimportant and the wave steepness, obtained by dividing the first variable by the second variable in (16), is the most important parameter.] For a given structure slope Figure 11 shows that as the wave steepness decreases, the relative run-up

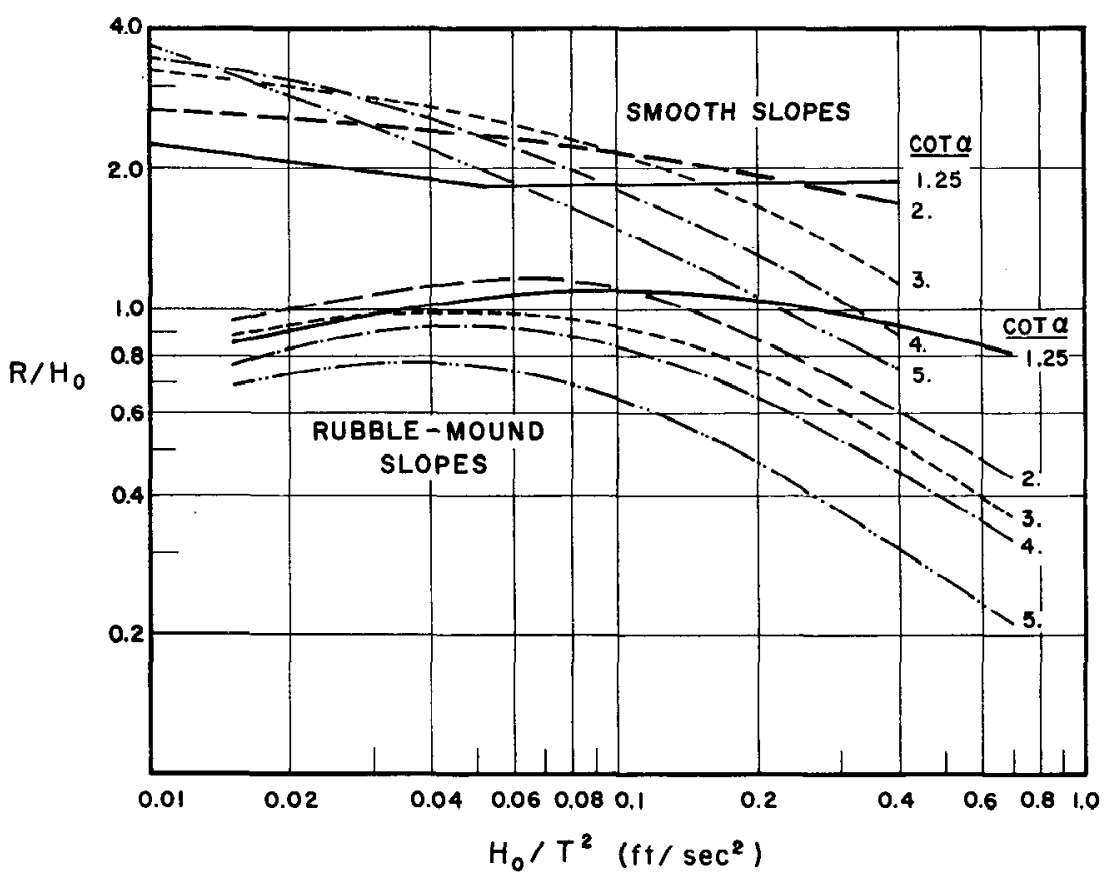

Figure 11 Wave run-up on smooth slopes and rubble-mound slopes $\left(h / H_{0}>3\right)(C E R C$, 1966). 
increases. In the region where $H_{0} / T^{2}<0.03 \mathrm{ft} / \mathrm{sec}^{2}$ the relative run-up generally increases with decreasing structure slope; the reverse is true for $H_{0} / T^{2}>0.1 \mathrm{ft} / \mathrm{sec}^{2}$.

In the lower part of Figure 11 the corresponding relative run-up for rubblemound slopes is shown. The experiments (Hudson, 1958) were conducted in the laboratory using regular waves with the run-up recorded before reflections from the wave machine interfered with waves at the structure. Each structure was composed of a reasonably uniform quarry-stone armor layer with an underlying core of crushed basalt (the mean particle diameter of the core was 0.125 in.) and therefore, the effects of the shape of the material, the packing, and the permeability of the structure are represented in the data. There is a significant reduction in run-up for the rubble-mound slope compared to the smooth impermeable slope; in fact, for comparable slopes the run-up on the rubble-mound is approximately one-half that for the smooth slope. These data indicate the importance of the parameter $\psi$ in (16). Similar to the run-up on smooth slopes, the run-up on the rubble-mound for a given slope increases as the wave steepness decreases; however, the relative run-up tends to reach a maximum for waves of small steepness and then decreases somewhat with decreasing wave steepness. Contrary to the run-up on smooth slopes, the run-up on the rubble-mound decreases with decreasing slope of the structure (increasing $\cot \alpha$ ) for the full range of wave steepness, again indicating that the effects of the permeability and the roughness of the rubble-mound face are important factors in run-up.

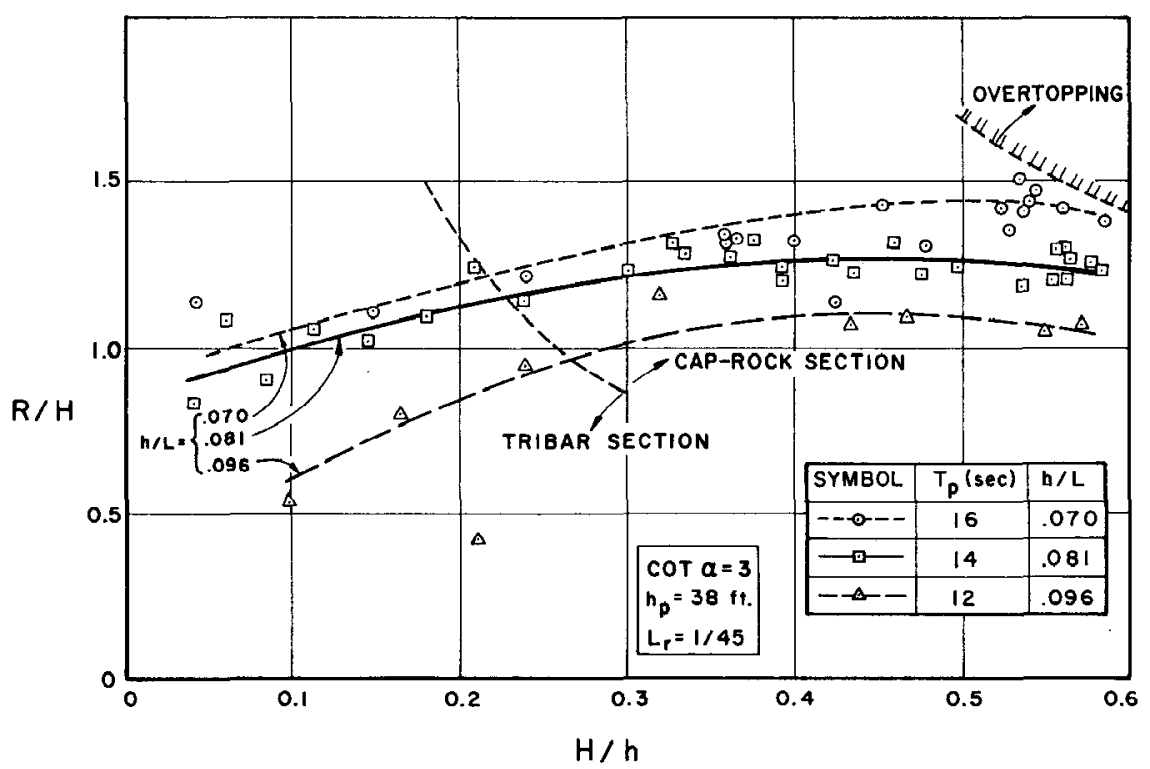

Figure 12 Relative run-up as a function of relative wave height (Vanoni \& Raichlen, 1966). 
For a structure face composed of a well-graded quarry-stone both the permeability and the roughness are reduced. The results of experiments with such a primary layer over an impermeable base (CERC, 1966) show an increase in relative run-up from 35 to $70 \%$ compared to the comparable case shown in Figure 11. These results again demonstrate the effect on run-up of the roughness and permeability of the structure and indicate the importance of properly modeling the structure to be tested in the laboratory.

Detailed experiments were conducted by Vanoni \& Raichlen (1966) to determine the stability and the run-up characteristics of a structure exposed to periodic waves. The primary armor layer of the structure was composed in part of tribars and in part of quarry-stone. An attempt was made in this study to view the run-up as described by (16) for a horizontal bottom offshore, that is, the variable $1 / m$ was neglected in the formulation of the problem. In these experiments the waves between the wave machine and the structure were allowed to reach a steady state, and the incident and reflected wave heights were determined from measurements of the partial standing-wave envelope. The slope of the structure face was $1: 3$ $(\cot \alpha=3)$ and the structure modeled in the laboratory was composed of the primary armor layer, an underlayer of quarry-stone, and a portion of the core of the proposed structure.

Selected data are presented in Figure 12 for one model scale $\left(L_{r}=1 / 45\right)$ where the graph shows run-up over wave height $H$ against $H$ over depth $h$. The structure was exposed to regular waves with three different wave periods; hence, curves are shown on Figure 12 for constant ratios of depth to wave length, $h / L$. Since the structure face was armored with tribars from the bottom up to a particular elevation and then with quarry-stone, one curve on Figure 12 shows the line of demarcation between these two materials; an additional curve indicates overtopping of the structure. Figure 12 shows that the relative run-up is a function of both $H / h$ and $h / L$ over the full range of the experiments; in fact, even for small values of the ratio of wave height to depth, the relative run-up is a function of $h / L$. General conclusions cannot be drawn from these limited data regarding the relative importance of the ratios of either depth to wave length or height to depth in affecting run-up, but both parameters appear important. It is difficult to compare the data in Figure 12 to the relative run-up for a rubble-mound structure of the same slope shown in Figure 11, since the effect of the ratio of depth to wave length is not shown in the latter. However, the smallest value of depth to wave length investigated by Hudson (1958) for a rubble-mound structure of the same slope was 0.10 and the relative run-up was about unity, which is approximately that shown in Figure 12 for a depth to wave length of 0.096 . Particular attention was given in this study to large wave height to depth ratios in contrast to the other studies mentioned, e.g., in the experiments for $h / L=0.07$ the ratio of the maximum wave height to the depth of water beneath the trough was approximately 0.65 .

Additional attention has been given in recent years to the run-up due to irregular waves. Since (16) has been derived for the case of regular waves, additional parameters are necessary to describe irregular waves. Basic differences 
in run-up for these two types of wave systems are shown in Figure 13, which shows selected results from the study conducted by Carstens, T $\phi$ rum \& Traetteberg (1966) discussed in Sect. 2.2. For the structure tested (a rubble-mound with a slope of $1: 1.25$, that is, $\cot \alpha=1.25$ ) the relative run-up for periodic waves is approximately the same as the maximum shown in Figure 11; however, for irregular waves it is apparent that the shape of the spectrum is important. For example, the run-up associated with the Berlevåg spectrum (B) in Figure 13 is significantly greater than that for either periodic waves or the broader model Neumann spectrum (N). (The spectra were shown in Figure 9.) Similar differences in run-up due to machine-generated irregular waves have been discussed by van Oorschot \& d'Angremond (1968) and for wind-generated waves by Webber \& Bullock (1968).

In an attempt to apply run-up data from regular wave experiments to structures exposed to irregular waves, Saville (1962) developed a frequency distribution of wave run-up from the distribution of wave steepness for a fully developed sea

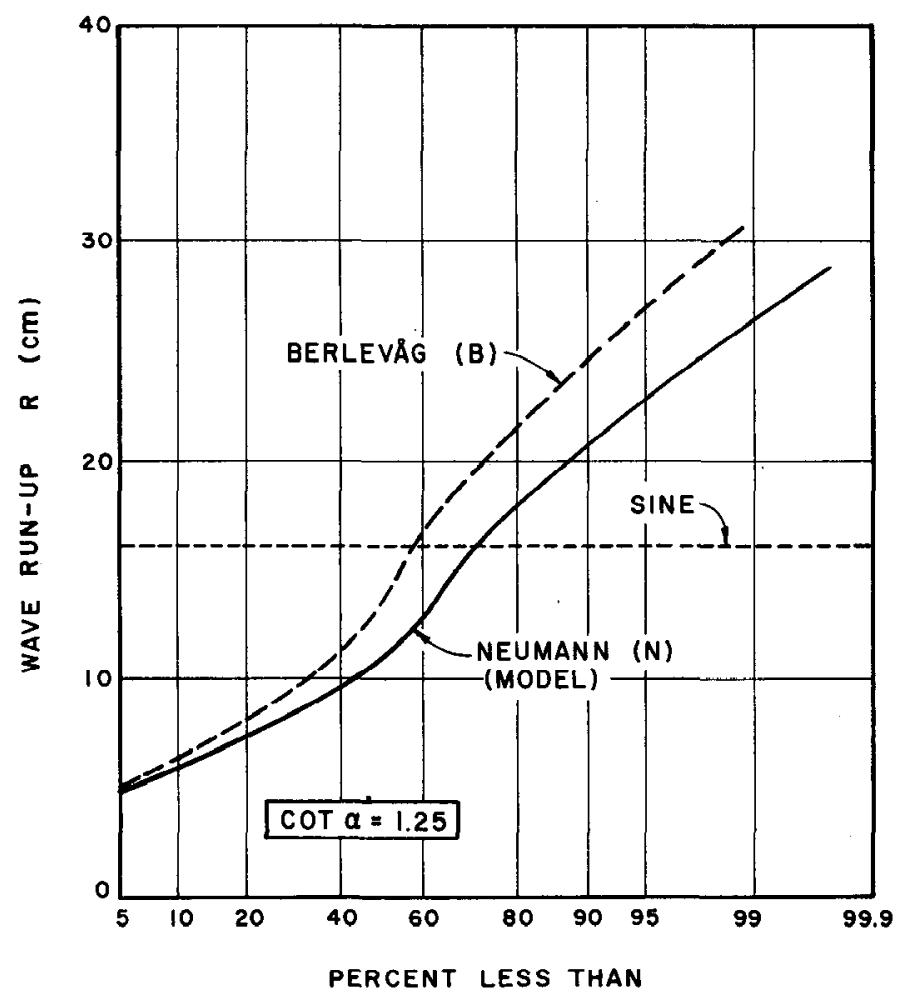

Figure 13 Wave run-up distribution for equal significant wave heights (Carstens, T $\phi$ rum \& Traetteberg, 1966). 
obtained from the joint distribution of wave height and wave period. In this way the approximate percentage of the wave train that could exceed the run-up as determined from periodic wave tests was defined. For rubble-mounds with slopes varying from $1: 1.5$ to $1: 6(1.5<\cot \alpha<6)$ it was found that approximately $20 \%$ of the time the run-up would be from one to two times that experienced with a wave with the height of the significant wave. These results are comparable to those shown in Figure 13.

A major problem associated with interpreting experimental run-up results in the design of coastal structures is the effect of model scale. Most research in this area has dealt with models of various scales, for example, see Saville (1958) as described in CERC (1966). In one investigation field measurements of run-up on the rubble-mound slope of an artificial island off the coast of Southern California were obtained. These measurements were made using a wave-staff gage mounted parallel to the slope of the structure and were compared to the results of laboratory tests of run-up using periodic incident waves (personal communication from P. Aagaard); the length scale of the laboratory experiments was $1 / 50$. Selected data obtained in the field and in the laboratory are shown in Figure 14 where the ordinate is the run-up measured in feet and the abscissa is the wave height in feet. For the field measurements, the run-up was ranked in order of descending magnitude and plotted as a function of the wave height measured off the structure ranked in the same way; thus the maximum run-up corresponds to the maximum wave height for a given record. For the laboratory data, the run-up is plotted as a function of the causitive wave, with both scaled up to the prototype, and the wave period indicated corresponds to the prototype period. Figure 14 shows that the run-up obtained from field measurements was considerably larger than that determined in the laboratory: the relative run-up, $R / H$, varied from 1.26 to 1.76 for the field data compared with slightly less than 1.26 for the laboratory results. There are at least two possible reasons for this difference; the scale effect (or Reynolds-Number effect) mentioned previously and the effect of the irregular waves for the field measurements. Due to viscous effects, CERC (1966) recommends that run-up measured in the laboratory for small-scale experiments be increased by 15 to $20 \%$ in applying the data to the full-size structure. If a similar factor is applied to the laboratory data shown in Figure 14, most experimental results would fall between a relative run-up of 1.26 and 1.52. If, in addition, the effect of frequency distribution of wave run-up were included, the laboratory data would agree more closely with the field data. These are a very limited sample of the data needed to more accurately relate laboratory run-up experiments to field conditions.

\section{WAVE TRANSMISSION}

Usually the function of a breakwater is to protect a harbor or section of the coastline from wave attack with the breakwater acting as a wave attenuator. Therefore, in the overall design of a breakwater the magnitude of energy transmitted past the structure must be considered. Excluding the transmission of energy around 


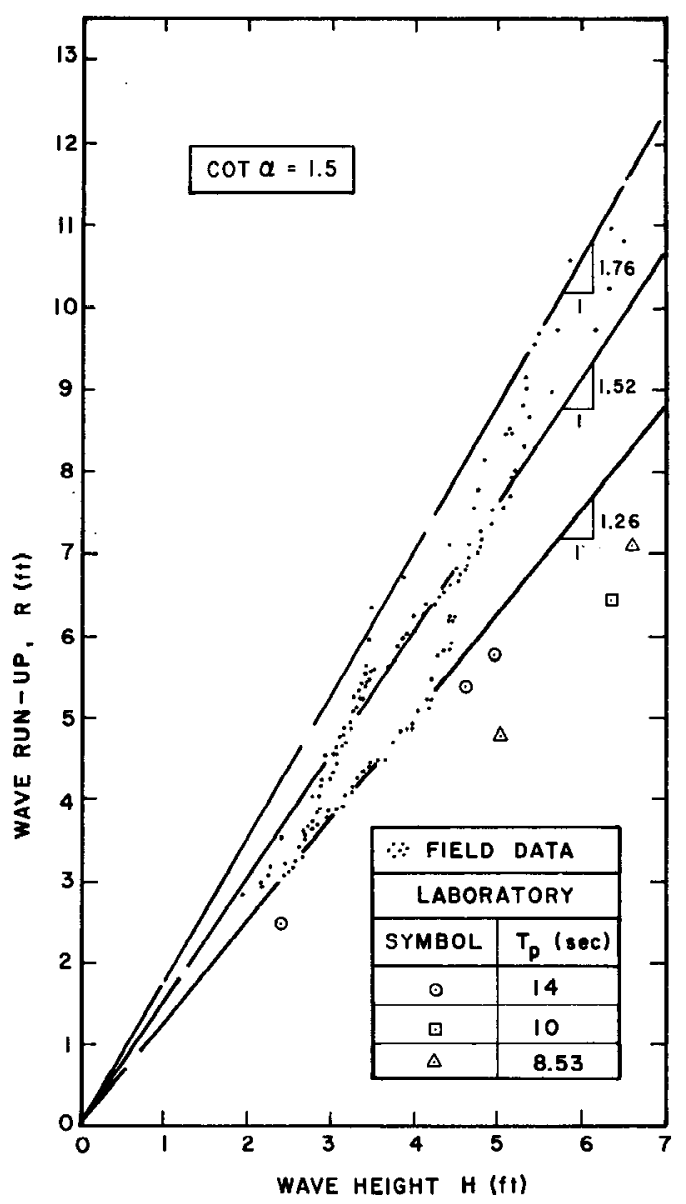

Figure 14 Wave run-up as a function of wave height, prototype vs model (personal communication from $\mathbf{P}$. Aagaard).

the ends of the breakwater, wave transmission can occur in at least two ways: by run-up and subsequent overtopping of the structure, and by transmission through the breakwater due to the permeable nature of a rubble-mound. Various aspects of this problem have been studied in the laboratory, and some of the results are discussed in this section, including also the associated scale effects that are important when interpreting laboratory experiments.

Saville, Garcia \& Lee (1965) have discussed transmission of waves both over and through breakwaters. In a study of wave transmission over low-crested breakwaters they found 1 . for a given crest width, as the elevation of the crest increased, the height of the transmitted wave decreased significantly, and 2. for a 
given crest elevation, as the width of the breakwater crest increased, the transmitted wave height also decreased. Both results are expected and are determinations that must be made in connection with a particular design.

In two papers Cross \& Sollitt (1972) and Sollitt \& Cross (1972) discuss transmission of regular waves due to overtopping and to transmission through a permeable structure. Cross \& Sollitt (1972) developed a method to predict transmission by relating the estimated energy flux past a structure due to overtopping to the flux of energy associated with the transmitted wave. An analysis is presented for nonbreaking waves arriving at normal incidence to a breakwater that is a function of certain parameters that must be experimentally evaluated. The wave transmission correlates with the ratio of the crest elevation above the still water level to the run-up that would be experienced if the breakwater were of unlimited height. The transmission coefficient, defined as the ratio of transmitted to incident wave heights, decreases as the ratio of the crest elevation to this hypothetical run-up increases. Sollitt \& Cross (1972) investigate analytically and experimentally the transmission of wave energy through a rectangular permeable homogeneous breakwater and through an idealized trapezoidal breakwater of layered construction. With a rectangular structure the transmission through the breakwater decreases with increasing incident wave steepness and with increasing depth-to-wavelength ratio. The transmission coefficient varies in a similar fashion for the trapezoidal structure. This is in agreement with observations in nature where rubble-mounds may be relatively transparent to very long-period waves of small steepness but opaque to shorter-period waves.

Kondo \& Toma (1972) investigated the wave reflection and transmission through a porous structure composed of a lattice of circular cylinders. If this structure is considered as an idealized breakwater, some interesting effects are observed. Similar to the work of Sollitt \& Cross (1972), the transmission coefficient decreased with increasing depth-to-wavelength ratio and also with increasing wave steepness. In addition, the ratio of structure length to wavelength had an important effect on the transmission coefficient: as this ratio increased the transmission coefficient decreased significantly. Also, the reflection coefficient was a periodic function of the ratio of structure length to wave length.

Wave transmission through an idealized rectangular breakwater composed of spheres or cubes was investigated by Kamel (1969). As the ratio of depth to wave length decreased, the transmission coefficient increased, and as the wave steepness increased, the transmission through the idealized breakwater decreased, similar to the observations of others. The ratio of structure length to wave length also had an effect on the transmission coefficient.

Since the transmission of wave energy through a rubble-mound is a function of the structure permeability, the scale of laboratory experiments becomes important in applying the measured transmission coefficient to real structures. Several investigators have studied the problem of scale effects: Johnson, Kondo \& Wallihan (1966), Delmonte (1972), and Wilson \& Cross (1972). In all cases an effect of Reynolds Number was found to exist.

Three models of a rectangular breakwater consisting of crushed stone were 


\section{RAICHLEN}

investigated by Johnson, Kondo \& Wallihan (1966); the Froude Law was used for scaling, with the structure composed of the largest rock considered the "prototype." The structure composed of the smallest rock exhibited a reduced transmission coefficient over the full range of wave steepness tested compared to the structures composed of larger material. For small wave steepness the transmission coefficient was approximately one-half that for the "prototype."

Clearly these results indicate a need for additional investigations of both the problem of the transmission of wave energy through and over rubble-mounds as well as the effect of the model scale on interpreting experimentally determined transmission coefficients.

\section{OVERTOPPING}

Overtopping of a rubble-mound by waves affects the stability of the structure and the waves transmitted past the structure. In Sect. 4 attention was given to the latter; in this section, the effect of overtopping on the stability of the structure and the quantity of overflow for shore structures is discussed.

Since an important economic consideration in breakwater design is the maximum elevation of the crest, to reduce costs the crest elevation may be lowered to permit significant overtopping by waves during an extreme storm. Hence, the water jet associated with the overtopping wave can impinge directly on the shoreward face of the breakwater, which during normal wave conditions is protected from this. This may lead to instability of the armor on the shoreward face of the rubblemound for the same waves for which the seaward face was stable; only limited data are available on this aspect of stability.

Lording \& Scott (1971) present useful information in this regard from experiments conducted to investigate the stability of a rubble-mound constructed of quarry-stone under the condition of overtopping. It was found that the stability of the shoreward face may be a more reliable index than the seaward face for the estimation of armor size in an expression such as (12a). In a scnsc these observations are in agreement with those of Raichlen (1972), where a study was conducted in the laboratory specifically to investigate stability of the shoreward face of a breakwater under the condition of overtopping where the armor-layer was composed of tribars. Raichlen (1972) found that the necessary weight of stable armor units on the shoreward face was nearly twice that which would be required on the seaward face, due to the violent jet action associated with overtopping. However, it was apparent that (12a) could not be applied to the shoreward face of the structure for this case, since decreasing the slope of the shoreward face of the breakwater did not improve the stability of the armor for a given wave height but actually made it less stable. The reason is that the stability of armor on the shoreward face of an overtopped rubble-mound is affected primarily by impingement of the overtopping jet on the structure and the ensuing flow down the face. When the shoreward face is relatively steep the jet impinges on the still-water surface on the shoreward face and the structure face is exposed to smaller velocities at the same distance from the crest than for the case of less steep shoreward slope. 
It is apparent that this problem is important in understanding the effect of overtopping on a structure and needs additional attention. This is especially true because of the economic considerations which seldom permit design for noovertopping.

Detailed consideration of the question of the quantity of overtopping for structures located at the coast is beyond the intended scope of this review; however, because of its importance in understanding the problems associated with overtopping, it will be mentioned briefly. Several investigators have treated this problem: Tsuruta \& Goda (1968), Shiraishi \& Numata (1968), Paape (1960), Sibul \& Tickner (1956), Saville (1955), and Nagai \& Takada (1972). Only the first of this group are discussed in this section.

Tsuruta \& Goda (1968) present interesting results comparing the discharge expected due to overtopping of two seawalls by regular and irregular waves. One structure was composed of a vertical wall and the other of a vertical wall with a rubble-mound constructed seaward of the wall. An approach is presented by which regular wave data can be used to predict the overtopping effect of irregular waves. For a given crest elevation above the still-water level the discharge increases to a maximum and then decreases as a function of increasing significant wave height for a given depth. This effect is most striking for the case of a rubblemound seaward of the wall, indicating that wave breaking on the structure has an effect in reducing overtopping discharge. A comparison of the two different structures indicates that, for a given incident wave height and seawall height, the vertical-wall type of seawall has a significantly greater incidence of overtopping compared with a rubble-mound just seaward of the structure.

\section{Literature Cited}

Ahrens, J. P. 1970. Proc. Conf. Coastal Eng. 12th, $1557-66$

Beaudevin, C. 1955. La Houille Blanche 10: 332-39

Brandtzaeg, A. 1965. XXI Perm. Int. Assoc. Navig. Congr. Sect. II, Subj. I: Gen. Rep. $20 \mathrm{pp}$.

Carstens, T., T $\phi$ rum, A., Traetteberg, A. 1966. Proc. Conf. Coastal Eng. 10th, 958-71

CERC (U.S. Army Coastal Eng. Res. Cen.) 1966. Tech. Rep. 4

Cross, R. H., Sollitt, C. K. 1972. J. Waterways Harbors Div. Proc. ASCE 98:295309

Dai, Y. B., Kamel, A. M. 1969. U.S. Army Eng. Waterways Exp. Sta. Res. Rep. H-69-2

Danel, P. 1952. Nat. Bur. Stand. Circ. 521: 35-38

Delmonte, R. C. 1972. Proc. Conf. Coastal Eng. 13th, 1867-72

Font, J. B. 1970. Proc. Conf. Coastal Eng. 12th, 1567-85

Font, J. B. 1968. Proc. Conf. Coastal Eng. 11th, 779-86

Galvin, C. J. 1968. J. Geophys. Res. 73(12): 3651-59

Hudson, R. Y. 1974. U.S. Army Eng. Waterways Exp. Sta. Misc. Pap. H-74-2

Hudson, R. Y. 1959. J. Waterways Harbors Div. Proc. ASCE 85, no. WW3:93-121

Hudson, R. Y. 1958. U.S. Army Eng. Waterways Exp. Sta. Rep. 2-2

Hudson, R. Y., Jackson, R. A. 1959. U.S. Army Eng. Waterways Exp. Sta. Misc. Pap. $2-296$

Hudson, R. Y., Jackson, R. A. 1953. U.S. Army Eng. Waterways Exp. Sta. Tech. Mem. 2-365

Iribarren-C., R. 1965. XXI Perm. Int. Assoc. Navig. Congr. Sect. II, Subj. 1:15-46 (1 fold-out)

Iribarren-C., R., Nogales-O., C. 1953. XVIII Perm. Int. Assoc. Navig. Congr. Sect. II, Subj. 3:119-39

Johnson, J. W., Kondo, H., Wallihan, R. 1966. Proc. Conf. Coastal Eng. 10th, 102224

Kamel, A. M. 1969. U.S. Army Eng. Waterways Exp. Sta. Res. Rep. H-69-1 
Kidby, H. A., Powell, S. B., Roberts, A. L. 1964. J. Waterways Harbor Div. Proc. ASCE 90, no. WW4:77-85

Kondo, H., Toma, S. 1972. Proc. Conf. Coastal Eng. 13th, 1847-66

Lording, P. T., Scott, J. R. 1971. J. Waterways Harbors Div. Proc. ASCE 97:341-54

Merrifield, E. M., Zwamborn, J. A. 1966. Proc. Conf. Coastal Eng. 10th, 885-912

Morison, J. R., O'Brien, M. P., Johnson, J. W., Schaaf, S. A. 1950. Am. Inst. Mining, Metall. Petr. Eng., Petr. Trans. 189 (TP2846) : 149-54

Nagai, S. 1962. J. Waterways Harbor Div. Proc. ASCE 88, no. WW3:85-115

Nagai, S., Takada, A. 1972. Proc. Conf. Coastal Eng. 13th, 1975-91

Paape, A. 1960. Proc. Conf. Coastal Eng. 7th, 674-81

Plate, E. J., Nath, J. H. 1969. J. Waterways Harbors Div. Proc. ASCE 95:491-511

Raichlen, F. 1972. J. Waterways Harbor Div. Proc. ASCE $98: 273-79$

Savile, L. H. 1940. J. Inst. Civ. Eng. 15: $1-26$

Saville, T. Jr. 1962. Proc. Conf. Coastal Eng: 8 th, $48-59$

Saville, T. Jr. 1958. U.S. Army Eng. Beach
Erosion Bd. Unpublished

Saville, T. Jr. 1956. J. Waterways Harbor Div. Proc. ASCE 82, 925(1)-925(14)

Saville, T. Jr. 1955. U.S. Army Eng. Beach Erosion Bd. Tech. Mem. 64

Saville, T. Jr., Garcia, W. J., Lee, C. E. 1965. XXI Perm. Int. Assoc. Navig. Congr. Sect. II, Subj. 1:229-53

Shiraishi, N., Numata, A., Endo, T. 1968. Proc. Conf. Coastal Eng. 11th, 853-69

Sibul, O. J., Tickner, E. G. 1956. U.S. Army Eng. Beach Erosion Bd. Tech. Mem. 80

Sollitt, C. K., Cross, R. H. 1972. Proc. Conf. Coastal Eng. 13th, 1827-46

Svee, R., Traetteberg, A., Tørum, A. 1965. XXI Perm. Int. Assoc. Naviq. Congr. II(1): $133-62$

Tsuruta, S., Goda, Y. 1968. Proc. Conf. Coastal Eng. 11th, 833-52

Vanoni, V.A., Raichlen, F. 1966. W. M. Keck Lab. Hydraul. Water Resources Cal. Inst. Technol. Rep. KH-R-14

van Oorschot, J. H., d'Angremond, K. 1968. Proc. Conf. Coastal Eng. 11th, 888-900

Webber, N. B., Bullock, G. N. 1968. Proc. Conf. Coastal Eng. 11th, 870-87

Wilson, K. W., Cross, R. H. 1972. Proc. Conf. Coastal Eng. 13th, 1873-84 


\section{CONTENTS}

Some Memories of Early Work in Fluid Mechanics at the Technical UNIVERSITY OF DELFT, J. M. Burgers

Pressure Fluctuations Beneath Turbulent Boundary Layers, $W . W$. Willmarth

Nonlinear Thermal Convection, Enok Palm

Relaxation Methods in Fluid Mechanics, Harvard Lomax and Joseph L. Steger

Experiments in Granular Flow, $K$. Wieghardt

Flow Lasers, Walter H. Christiansen, David A. Russell, and Abraham Hertzberg

The Structure and Dynamics of Vortex Filaments, Sheila E. Widnall 141

Fluid Mechanics of Heat Pipes, C. L. Tien

Fluid Mechanics of Waste-Water Disposal in the Ocean, Robert C. Y. Koh and Norman H. Brooks

HemodynamiCs, H. L. Goldsmith and R. Skalak

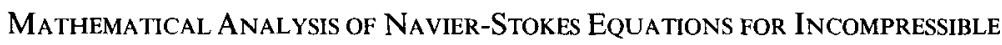
Liquids, O. A. Ladyzhenskaya

EXPERIMENTS IN Rotating and Stratified Flows: OCEANOGRAPHIC Application, T. Maxworthy and F. K. Browand

New Trends in Experimental Turbulence Research, John Laufer 307

The Effect of Waves on Rubble-Mound Structures, Fredric Raichlen 327

Hydrodynamics of LaRge Lakes, G. T. Csanady 357

\section{INDEXES}

AUTHOR INDEX

Cumulative Index of Contributing Authors, Volumes 3-7 394

Cumulative IndeX of Chapter Titles, Volumes 3-7 